\title{
Pattern-reversal electroretinograms and visual evoked cortical potentials in multiple sclerosis
}

\author{
HANS E. PERSSON AND PETER WANGER \\ From the Departments of Clinical Neurophysiology and Ophthalmology, Karolinska Hospital, \\ S-10401 Stockholm, Sweden
}

\begin{abstract}
SUMmaRY Pattern-reversal and flash electroretinograms (ERG) and visual evoked cortical potentials (VECP) were recorded from 15 patients with definite multiple sclerosis (MS). All patients had prolonged VECP latency, indicating demyelination of one or both optic nerves. The pattern-reversal ERG amplitude was reduced below the level of normal variation (mean $-2 \mathrm{SD}$ ) in 11 of the 22 eyes with prolonged VECP latency and in one of the eight eyes with normal VECP latency. The mean pattern-reversal ERG amplitude from eyes with prolonged VECP latencies was significantly lower than the mean amplitude from the normal controls. No abnormalities were observed in the flash ERGs. Degeneration of retinal ganglion cell axons has been demonstrated in MS patients. The amplitude reduction in the pattern-reversal ERG, observed in some $50 \%$ of the eyes with prolonged VECP latencies, is supposed to reflect retinal ganglion cell dysfunction or degeneration secondary to demyelination of the optic nerve.
\end{abstract}

In multiple sclerosis (MS) the optic nerve is one of the sites of predilection for demyelination. Prolonged latency in the pattern-reversal visual evoked cortical potential (VECP) has been widely accepted as a reliable sign of these optic nerve changes. ${ }^{1-3}$ Loss of axons may take place in chronic plaques of demyelination. ${ }^{4}$ Nerve fibre layer defects, indicating such secondary axonal degeneration, has been demonstrated in the maculopapillar bundles of the retina by red-free fundus photography in MS patients. ${ }^{56}$

Studies of the pattern electroretinogram (ERG) in normal subjects have led to the identification of a pattern evoked component, showing spatial frequency tuning ${ }^{7-10}$ and temporal characteristics, ${ }^{11}$ which conforms with the expected response properties of the retinal ganglion cells. A luminance-evoked component has also been isolated ${ }^{7}$ and the pattern ERG has been proposed to be a response to local luminance changes only. ${ }^{1012} 13$ However, results from animal experiments ${ }^{14}$ and findings in several studies ${ }^{15-20}$ of patients with retinal and optic nerve disorders have supported the notion that the pattern ERG reflects retinal ganglion cell activity.

Little information is available regarding pattern ERGs in MS. Arden et al. ${ }^{18}$ mentioned that the

Correspondence to Dr Hans E. Persson. pattern ERG amplitude 'frequently' was reduced in MS patients and Boback et al. ${ }^{21}$ reported abnormal pattern ERGs from two eyes in five cases of MS.

The present study was made in order to find out if a systematic relationship could be demonstrated between pattern ERG changes and VECP latency prolongation in MS patients.

\section{Materials and methods}

Ten normal subjects, aged 23 to 43 years, six men and four women, constituted the reference group. Fifteen patients, aged 22 to 47 years, nine men and six women, with a clinical diagnosis of multiple sclerosis in a stable state were examined. Verbal consent was obtained from each individual prior to the examination after the aim of the study and the possible discomforts had been explained. Clinical data are summarised in Table 1 . All patients had previously been examined at the laboratory and shown latency prolongation in the VECP as a sign of demyelination in the optic nerves, which was a prerequisite for selection to the present study. Four patients had no history of ophthalmological symptoms. Ten had suffered from optic neuritis, two of them bilaterally, more than six months before the present study, and two reported Uhthoff's symptom, that is, visual impair- 
Table 1 Clinical data

\begin{tabular}{|c|c|c|c|c|c|c|}
\hline \multirow{2}{*}{$\begin{array}{l}\text { Patient } \\
\text { no. }\end{array}$} & \multirow[t]{2}{*}{ Sex } & \multirow[t]{2}{*}{ Age } & \multicolumn{2}{|l|}{ Ophthalmological } & \multirow{2}{*}{$\begin{array}{l}\text { General neurological } \\
\text { symptoms }\end{array}$} & \multirow{2}{*}{$\begin{array}{l}\text { Isoelectric focusing } \\
\text { of the cerebrospinal } \\
\text { fluid }^{24}\end{array}$} \\
\hline & & & History & Findings & & \\
\hline 1 & $\mathbf{M}$ & 47 & 0 & 0 & Autonomic and motor & - \\
\hline 2 & $\mathbf{M}$ & 46 & ON dx, diplopia & 0 & Sensory & + \\
\hline 3 & $\mathrm{~F}$ & 44 & 0 & Pale disc $\mathrm{dx}$ & Sensory and motor & (Missing) \\
\hline 4 & $\mathbf{M}$ & 43 & 0 & 0 & Sensory and motor & + \\
\hline 5 & $\mathbf{M}$ & 43 & ONdx, Uhthoff bil & 0 & Sensory & + \\
\hline 6 & $\mathbf{M}$ & 42 & ON $\sin$ & 0 & Sensory & + \\
\hline 7 & $\mathrm{~F}$ & 40 & ON dx, diplopia & $\begin{array}{l}\text { Paresis nn IV, VI, VII } \\
\text { pale discs }\end{array}$ & Sensory and motor & + \\
\hline 8 & $\mathbf{M}$ & 40 & $\mathrm{ON} \sin$ & Pale disc sin & Sensory and motor & + \\
\hline 9 & $\mathbf{M}$ & 37 & Uhthoff $d x$ & 0 & Motor & + \\
\hline 10 & $\mathrm{~F}$ & 36 & ON dx & 0 & Motor & (Missing) \\
\hline 11 & $\mathbf{M}$ & 33 & 0 & Palc disc sin & Sensory & + \\
\hline 12 & M & 33 & ON bil & 0 & Sensory and motor & - \\
\hline 13 & $\mathrm{~F}$ & 29 & ON dx & $\begin{array}{l}\text { Pale disc col vis def } \\
\text { vis field def } \mathrm{dx}\end{array}$ & Sensory & (Missing) \\
\hline 14 & $\mathrm{~F}$ & 29 & ON bil & $\begin{array}{l}\text { Col vis def bil, vis field } \\
\text { def } d x\end{array}$ & Sensory & + \\
\hline 15 & $\mathbf{F}$ & 22 & ON sin & 0 & Sensory & - \\
\hline
\end{tabular}

$\mathrm{M}=$ male, $\mathrm{F}=$ female, $\mathrm{dx}=$ right, $\sin =\mathrm{left}$, bil=bilateral, $\mathrm{ON}=$ optic neuritis, col vis def $=$ colour visual defect, vis field def=visual field defect.

ment of short duration in connection with physical effort. ${ }^{22}$ Two patients had a history of diplopia. During the routine ophthalmological examinations of these patients no abnormal findings were reported in nine cases. All patients except two had normal visual acuity. Patient No 7 had bilateral visual acuity reduction (right eye $=0 \cdot 2$, left eye $=0.5$ ) and patient No 13 unilateral reduction (right eye=0.6). No patient had refractive error of the degree demonstrated to influence the pattern-reversal ERG amplitude. ${ }^{23}$ Pupil size was equal in both eyes of all patients and pupil reactions normal in 13 patients. Impaired pupil constriction to direct illumination (positive swinging light test) was observed in the right eye of patient No 13 and the left eye of patient No 15. Pale optic nerve discs were observed in one or both eyes in five cases, visual field and colour vision defects in two patients, and paresis of oculomotor nerves in one patient. General neurological symptoms included sensory disturbances in 12 cases, motor dysfunction in eight cases, and autonomic symptoms in one case. MS-specific pattern on isoelectric focusing of the cerebrospinal fluid ${ }^{24}$ was found in nine cases. This examination gave negative results in three cases and was not performed in three cases.

\section{STIMULATION}

The pattern-reversal stimulation was obtained with the aid of a Medelec television pattern generator. The black and white checkerboard pattern was presented on a standard 26 -inch $(66 \mathrm{~cm})$ television set giving a stimulating field of $15^{\circ}$ in the horizontal and $14^{\circ}$ in the vertical direction. The check-size was $48^{\prime}$ of arc when VECPs and 24' of arc when pattern-reversal ERGs were recorded. Contrast setting on the pattern generator was $50 \%$ and $100 \%$, giving a measured contrast of $45 \%$ and $75 \%$ respectively. Average luminance of the television screen was $45 \mathrm{~cd} / \mathrm{m}^{2}$ and the background illumination about $30 \mathrm{~cd} / \mathrm{m}^{2}$. The pattern-reversal rate was $1 \mathrm{~Hz}(2$ reversals/s). Flash ERGs were recorded to stimulation at $1 \mathrm{~Hz}$ with a GRASS MS2 photostimulator, intensity setting 8 , at a distance of $50 \mathrm{~cm}$ in front of the examined eye.

\section{RECORDING}

The VECP was recorded between an electrode applied to the scalp $5 \mathrm{~cm}$ above the inion in the midline $(\mathrm{Oz})$ and a midfrontal reference $(\mathrm{Fz})$. Monocular stimulation was used. The signals were amplified with low and high frequency filters set at $0 \cdot 8$ and $80 \mathrm{~Hz}$ respectively. Responses to 128 patternreversals were averaged on a Medelec DAV6 with an analysis time of $300 \mathrm{~ms}$. Latency of the response was defined as the time from the pattern-reversal to the point of maximal positivity (P 100) of the early component. The amplitude was measured from the preceding negative peak (N 75) to the trough of the positive wave (P 100).

The ERG was recorded with a gold-foil electrode ${ }^{25}$ inserted under the lower eye lid with a reference electrode attached to the skin $2 \mathrm{~cm}$ posterior to the lateral orbital rim. Binocular stimulation was used. The pattern-reversal ERG was recorded in light adapted state and amplified, averaged, and analysed as the VECP. The peak to peak amplitude was measured. Four to eight flash ERGs were recorded 
Table 2 Pattern-reversal VECP and ERG data

\begin{tabular}{|c|c|c|c|c|c|c|c|c|c|c|}
\hline \multirow[t]{3}{*}{ Patient No } & \multicolumn{4}{|c|}{$p-V E C P I$} & \multicolumn{4}{|c|}{$p-V E C P I I$} & \multicolumn{2}{|c|}{$p-E R G$} \\
\hline & $R E$ & & $L E$ & & $R E$ & & $L E$ & & $R E$ & $L E$ \\
\hline & $\begin{array}{l}\text { Lat } \\
m s\end{array}$ & $\begin{array}{l}\text { Ampl } \\
\mu V\end{array}$ & $\begin{array}{l}\text { Lat } \\
m s\end{array}$ & $\begin{array}{l}\text { Ampl } \\
\mu V\end{array}$ & $\begin{array}{l}\text { Lat } \\
m s\end{array}$ & $\begin{array}{l}\text { Ampl } \\
\mu V\end{array}$ & $\begin{array}{l}\text { Lat } \\
m s\end{array}$ & $\begin{array}{l}\text { Ampl } \\
\mu V\end{array}$ & $\begin{array}{l}\text { Ampl } \\
\mu V\end{array}$ & $\begin{array}{l}\text { Ampl } \\
\mu V\end{array}$ \\
\hline 1 & 129 & $5 \cdot 5$ & 120 & $5 \cdot 0$ & 133 & $3 \cdot 5$ & 116 & $4 \cdot 5$ & $2 \cdot 4$ & $3 \cdot 6$ \\
\hline 2 & 129 & $3 \cdot 0$ & 121 & $3 \cdot 5$ & 121 & $8 \cdot 0$ & 112 & $7 \cdot 0$ & $2 \cdot 8$ & $2 \cdot 8$ \\
\hline 3 & 126 & $5 \cdot 5$ & 152 & $4 \cdot(1)$ & 122 & $4 \cdot 5$ & 150 & $4 \cdot 5$ & $1 \cdot 8$ & 1.7 \\
\hline 4 & 123 & $4 \cdot(1)$ & 125 & $4 \cdot()$ & 117 & $4 \cdot 0$ & 119 & $3 \cdot 0$ & $2 \cdot 0$ & $2 \cdot 5$ \\
\hline 5 & 154 & $8 \cdot()$ & 159 & $8 \cdot 0$ & 160 & $5 \cdot 0$ & 160 & $7 \cdot 0$ & 1.7 & $1 \cdot 8$ \\
\hline 6 & 105 & $5 \cdot()$ & 128 & $8 \cdot()$ & 103 & $3 \cdot()$ & 128 & $3 \cdot 5$ & $3 \cdot 5$ & $3 \cdot 0$ \\
\hline 7 & 120 & $3 \cdot()$ & 109 & $4 \cdot()$ & 115 & $4 \cdot 5$ & 115 & $3 \cdot 5$ & $3 \cdot 3$ & $3 \cdot 3$ \\
\hline 8 & 118 & $6 \cdot()$ & 180 & $3 \cdot()$ & 110 & $7 \cdot 0$ & 140 & $4 \cdot 0$ & 0.9 & $1 \cdot 0$ \\
\hline 9 & 124 & $12 \cdot()$ & 110 & $7 \cdot 0$ & 134 & $8 \cdot 5$ & 112 & $7 \cdot 0$ & $4 \cdot 0$ & $4 \cdot 0$ \\
\hline 10 & 175 & $8 \cdot 0$ & 167 & $7 \cdot 0$ & 170 & $2 \cdot 5$ & 163 & $1 \cdot 5$ & $1 \cdot()$ & $1 \cdot 0$ \\
\hline 11 & 99 & $3 \cdot 0$ & 132 & $4 \cdot 0$ & 99 & $6 \cdot 0$ & 125 & $5 \cdot 0$ & 2.7 & $1 \cdot 5$ \\
\hline 12 & 111 & $3 \cdot 0$ & 139 & $3 \cdot 0$ & 107 & $5 \cdot()$ & 131 & $4 \cdot()$ & $2 \cdot 3$ & $2 \cdot 4$ \\
\hline 13 & 125 & $13 \cdot 0$ & 100 & $14 \cdot 0$ & 121 & $16 \cdot 0$ & 99 & $14 \cdot 0$ & $2 \cdot 7$ & $2 \cdot 7$ \\
\hline 14 & 162 & $4 \cdot 5$ & 158 & $5 \cdot 5$ & 170 & $7 \cdot 0$ & 145 & $6 \cdot 0$ & 1.9 & $1 \cdot 8$ \\
\hline 15 & 98 & $5 \cdot()$ & 115 & $7 \cdot()$ & 100 & $8 \cdot()$ & 111 & $9 \cdot 0$ & 3.9 & $3 \cdot 5$ \\
\hline
\end{tabular}

after 5 min of dark adaptation and averaged. No mydriatic drops were used. The amplitudes of the a and $b$ waves were measured from the isoelectric line.

The statistical significances were assessed by Student's $t$ test and a p value of $<0.05$ was considered significant.

The study was approved by the Ethical Committee of the Karolinska Hospital.

\section{Results}

In the reference group $(n=10)$ the mean $p^{n+t e r n-}$ reversal ERG amplitude was $3.1 \mu \mathrm{V}$ with a $S L$, of 0.5 $\mu \mathrm{V}$, and the latency to the peak of the positive wave ranged from 55 to $70 \mathrm{~ms} .{ }^{20}$ The upper normal limit for the VECP latency in the present age group was 113 ms (mean +2 SD) and the interocular difference was less than $7 \mathrm{~ms}$.2 The mean VECP amplitude was $7 \cdot 1$ $\mu \mathrm{V}, \mathrm{SD} 1.8 \mu \mathrm{V}$.

Table 2 presents the pattern-reversal ERG and VECP data. Records from patient No 11 are shown in Fig. 1. Six $(40 \%)$ of the 15 patients had unilateral, and the remaining patients bilateral, prolongation of the VECP latency ( $>113 \mathrm{~ms}$ ) at one or both examinations. Small VECP changes were observed between the examinations. Two patients (Nos 2 and 8) had bilateral VECP latency prolongation in the first but only unilateral in the second examination, and one patient (No 7) showed the reversed change. Two subgroups were defined based on the findings from the second VECP examination. One ( $2 \mathrm{~A})$ consisted of the eight eyes with normal VECP latency from the eight patients with unilateral VECP abnormality. The other (2 B) consisted of the 22 eyes (in all patients) with significant prolongation or interocular difference of the VECP latency. Table 3 presents the mean and SD of the ERG and VECP data in the different subgroups. The subgroup $2 \mathrm{~A}$ (normal VECP latency) had mean pattern-reversal ERG amplitude not significantly different from the reference group.

The subgroup 2B (prolonged VECP latency) had significantly reduced amplitude (mean $=2 \cdot 3, \mathrm{SD}=0.9$ $\mu \mathrm{V}$ ) in the pattern-reversal ERG compared with the reference group $($ mean $=3 \cdot 1, \mathrm{SD}=0.5 \mu \mathrm{V})$. The negative correlation $(r=-0 \cdot 55, n=30)$ between the VECP latency and the pattern-reversal ERG ampli-

Table 3 Mean and SD of the ERG and VECP data in the different subgroups

\begin{tabular}{|c|c|c|c|c|c|}
\hline & \multirow{2}{*}{$\begin{array}{l}\text { Pattern-reversal } \\
\text { ERG (peak to } \\
\text { peak) }\end{array}$} & \multicolumn{2}{|l|}{ Flash ERG } & \multicolumn{2}{|l|}{$V E C P$} \\
\hline & & a Wave & b Wave & $A m p l$ & Lat \\
\hline $\begin{array}{l}\text { 1. Reference group }(10 \text { subjects })(<113 \mathrm{~ms} \text { and } \\
\text { interocular diff. }<7 \mathrm{~ms}) \\
\text { 2. MS group ( } 15 \text { subjects) }\end{array}$ & $3 \cdot 1 \pm 0 \cdot 5 \mu \mathrm{V}$ & $53 \pm 22 \mu \mathrm{V}$ & $184 \pm 41 \mu \mathrm{V}$ & $7 \cdot 1 \pm 1 \cdot 8 \mu \mathrm{V}$ & $103 \pm 5 \mathrm{~ms}$ \\
\hline $\begin{array}{l}\text { A. Normal VECP latency }(8 \text { cyes }) \\
\text { B. Prolonged VECP latency }(22 \text { eyes })(>113 \mathrm{~ms} \text { or }\end{array}$ & $2 \cdot 9 \pm 1 \cdot 0 \mu \mathrm{V}$ & $63 \pm 36 \mu \mathrm{V}$ & $207 \pm 69 \mu \mathrm{V}$ & $7 \cdot 1 \pm 3 \cdot 2 \mu \mathrm{V}$ & $105 \pm 6 \mathrm{~ms}$ \\
\hline interocular diff. $>7 \mathrm{~ms}$ ) & $2 \cdot 3 \pm 0 \cdot 9 \mu \mathrm{V}$ & $56 \pm 26 \mu \mathrm{V}$ & $197 \pm 57 \mu \mathrm{V}$ & $5 \cdot 4 \pm 3 \cdot 1 \mu \mathrm{V}$ & $135 \pm 9 \mathrm{~ms}$ \\
\hline
\end{tabular}



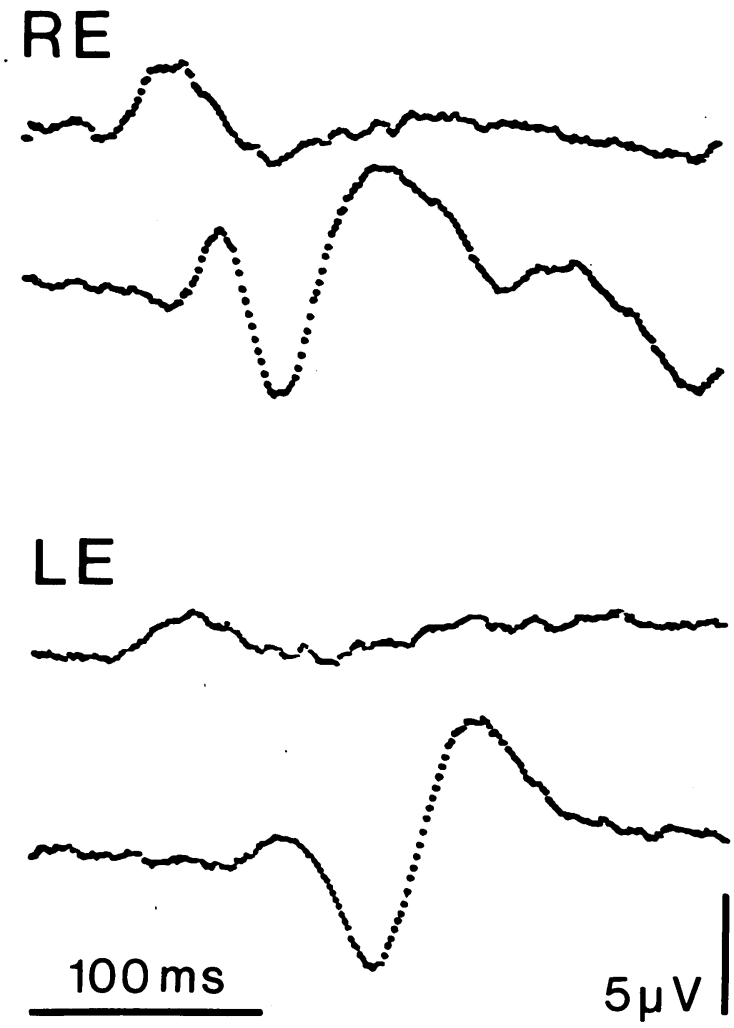

Fig. 1 Pattern-reversal ERGs (upper records, positivity upwards) and VECPs (lower records, positivity downwards) from patient $\mathrm{No} 11$ ( $R E=$ right eye; $L E=$ left eye). Note amplitude reduction of the ERG and latency prolongation of the VECP from the left eye.

tude was statistically significant. The mean amplitude of the VECP was lower in the subgroup 2B (prolonged VECP latency). However, the difference was not statistically significant when compared with the mean values from subgroup $2 \mathrm{~A}$ or the normal controls. No significant differences were found between the subgroups regarding flash ERG amplitudes.

When clinical and electrophysiological data were compared, no significant differences were observed in pattern-reversal ERG amplitude or VECP latency and amplitude between patients with and patients without a history of optic neuritis. Ophthalmoscopy revealed pale optic discs in six eyes. No differences were found in the electrophysiological parameters of these patients when compared with the remaining patients. Each of the following ophthalmological findings-visual acuity reduction, abnormal pupillary reactions, visual field and colour vision defects-was observed in two patients only, obviously too few for comparison.

\section{Discussion}

In the present study reduced pattern-reversal ERG amplitude was observed in about $50 \%$ of the MS patients with prolonged VECP latency as a sign of demyelination of the optic nerves. The reduction of pattern ERG amplitude was correlated with the degree of latency increase in the VECP. No changes were observed in the flash ERG. There was no correlation between the pattern-reversal ERG amplitude reduction and the history of optic neuritis or the observation of pale optic discs during ophthalmological examination.

Fiorentini et al. ${ }^{15}$ recorded the ERG to alternating gratings in three cases with optic neuritis and reported reduced amplitude in one case. This patient had optic neuritis in an acute stage with impairment of visual acuity. Arden et al.$^{18}$ reported reduced pattern ERG amplitude from the affected eye in patients after a delay of 10 weeks from the acute optic neuritis and also mentioned that the pattern ERG was reduced in MS patients. No patient in the present study had suffered from optic neuritis during the last six months before the examination. Recently Boback et al. ${ }^{21}$ recorded abnormal pattern ERG from two eyes in five cases of MS.

Changes in the pattern-reversal ERG have been described as amblyopia, ${ }^{232627}$ optic nerve disorders, ${ }^{1619}$ and glaucoma. ${ }^{171820}$ None of these disorders was present among the patients in the examined group.

Refractive errors have been demonstrated to influence the pattern-reversal ERG amplitude. ${ }^{2327}$ No patient in the present study had refractive error to the degree which reduces the ERG amplitude. The VECP latency prolongation is a reliable sign of demyelination of the optic nerve. ${ }^{1-3}$ However, prolonged VECP latency has also been observed in retinal disorders. ${ }^{28}{ }^{29}$ In our patients no retinal abnormalities were noted during ophthalmological examination, and all cases had normal flash ERG. Thus the latency prolongation in the VECP was considered to reflect optic nerve demyelination.

Ikeda et al. ${ }^{30}$ studied the flash ERG in patients with optic nerve disorders and found normal ERG functions when latency prolongation was the only abnormality in the VECP. In patients with amplitude reduction in the VECP subnormal ERG functions could be demonstrated, though the ERG results varied widely from one patient to another. During the course of the present study several check sizes and contrast levels were used in the stimulus pattern when the pattern ERG and VECP was recorded and several stimulus intensities when the flash ERG was recorded. Since no additional information was obtained, only data from our standard methods ${ }^{2022} 23$ 
are reported here. However, it cannot be excluded that the more elaborate method for ERG examination used by Ikeda et $a l .{ }^{30}$ might have shown abnormalities in some of our patients with subnormal VECP amplitude in addition to prolonged latency, for example, patient No 10, Table 2.

Although MS typically spares neurons, there are strong histopathological indications that some loss of axons has taken place in chronic plaques. ${ }^{4}$ Moreover, degeneration of retinal ganglion cell axons in MS patients has been demonstrated by Frisen and Hoyt ${ }^{5}$ and Tagami ${ }^{\circ}$ using red-free fundus photography. Thus the amplitude reduction in the pattern ERG from eyes with VECP signs of demyelination in the optic nerve is supposed to reflect deficient function or degeneration of retinal ganglion cells. The finding may lend support to the view that these cells are important for the generation of the pattern ERG. ${ }^{14}$

The authors are grateful to Charlotta Johansson, Carina Skogsberg, Arne Wiberg, and Britten Winström for assistance during the ERG and VECP examinations.

Supported by grants from the Karolinska Institute and from Carmen and Bertil Regner's Fund for Ophthalmological Research.

\section{References}

1 Halliday AM, ed. Evoked potentials in clinical testing. Clinical neurology and neurosurgery monographs. Edinburgh: Churchill Livingstone, 1982; 3: 187-234.

2 Chiappa KH, Ropper AH. Evoked potentials in clinical medicine. N Engl J Med 1982; 306: 1140-50.

3 Shibasaki H, Kuroiwa Y. Pattern reversal visual evoked potentials in Japanese patients with multiple sclerosis. $J$ Neurol Neurosurg Psychiatry 1982; 45: 1139-43.

4 Ludwin SK. Pathology of demyelination and remyelination. In: Waxman GW, Ritchic JM, eds. Demyelinating diseases. Basic and clinical electrophysiology. Advances in neurology. New York: Raven Press, 1981: 123-168.

5 Frisen L, and Hoyt WF. Insidious atrophy of retinal nerve fibers in multiple sclerosis. Fundoscopic identification in patients with and without visual complaints. Arch Ophthalmol 1974; 92: 91-7.

6 Tagami Y. Atrophy of maculopapillar bundles in rec. deptic neuropathics. Jpn J Ophthalmol 1979: 23: 301-9.

7 Korth M. Pattern-evoked responses and luminance-evoked responses in the human electroretinogram. $J$ Physiol (Lond) 1983; 337: 451-69.

8 Odom VJ, Maida TM, Dawson WW. Pattern evoked retinal response (PERR) in humans: effects of spatial frequency, temporal frequency, luminance and defocus. Curr Eye Res 1982 . 2: 99.

9 Sokol S, Jones K, Nadler D. Comparison of the spatial response properties of the human retina and cortex as measured by simultaneously recorded pattern ERGs and VEPs. Vision Res 1983; 23: 723-7.

10 Arden GB, Vacgan. Electroretinograms evoked in man by local uniform or patterned stimulation. J Physiol (Lond) 1983; 341: 85-104.
11 Trick GL, Wintermeyer DH. Spatial and temporal frequency tuning of pattern-reversal retinal potentials. Invest Ophthalmol Visual Sci 1982; 23: 774-9.

12 Spekrejse H. Estevez O, van der Tweel LH. Luminance responses to pattern reversal. Proceedings of the Xth ISCERG Symposium. Doc Ophthalmol Proc Ser 1973; 2: 205-12.

13 Ricmslag FCC. Ringo J. Spekrejse H, Verduyn Lunel HFE. The distinction between luminance and spatial components in the pattern ERG. Proceedings of the XX ISCEV Symposium. Doc Ophthalmol Proc Ser 1983; 37: 255-64.

14 Maffei L. Fiorentini A. Electroretinographic responses to alternating gratings hefore and after section of the optic nerve. Science 1981; 211: 953-5.

15 Fiorentini A, Maffei L. Pirchio M, Spinelli D, Porchiatti V. The ERG in response to alternating gratings in patients with diseases of the peripheral visual pathway. Invest Ophthalmol Visual Sci 1981: 21: 490-3.

16 Dawson WW, Maida TM, Rubin ML. Human pattern-evoked retinal responses are altered by optic atrophy. Invest Ophthalmol Visual Sci 1982; 22: 796-803.

17 May JG, Ralston JV. Reed JL, Van Dyck HJL. Loss in patternelicited electroretinograms in optic nerve dysfunction. $A m J$ Ophthalmol 1982; 93: 418-422.

18 Arden GB, Vacgan, Hogg CR. Clinical and experimental evidence that the pattern electroretinogram (PERG) is generated in more proximal retinal layers than the focal electroretinogram (FERG). In: Bodis-Wollner I, ed. Evoked potentials. Ann N Y Acad Sci 1982; 388: 580-60)7.

19 Price MJ, Sciple WH, Kupfersmith MJ, Siegel IM, Carr RE. The pattern electroretinogram in the assessment of optic nerve discase. Ophthalmology 1982; 89: 134.

20) Wanger P, Persson HE. Pattern-reversal electroretinograms in unilateral glaucoma. Invest Ophthalmol Visual Sci 1983; 24: 74953.

21 Boback P, Bodis-Wollner I, Harnois C, et al. Pattern electroretinograms and visual evoked potentials in glaucoma and multiple sclerosis. Am J Ophthalmol 1983; 96: 72-83.

22 Persson HE, Sachs C. Visual evoked potentials elicited by pattern reversal during provoked visual impairment in multiple sclerosis. Brain 1981; 104: 369-82.

23 Persson HE, Wanger P. Pattern-reversal electroretinograms in squint amblyopia, artificial anisometropia and simulated eccentric fixation. Acta Ophthalmol (Khh) 1982; 60: 123-32.

24 Kjellin KG. Vesterberg O. Isoclectric focusing of cerebrospinal fluid in neurological discases. J Neurol Sci 1974: 23: 199-213.

25 Arden GB, Carter RM. Hogg C. Siegel IM, Margolis S. A gold foil electrode: extending the horizons for clinical electroretinography. Invest Ophthalmol Visual Sci 1979: 18: 421-6.

26 Sokol S, Nadler D. Simultaneous electroretinograms and visual evoked potentials from adult amblyopes in response to a pattern stimulus. Invest Ophthalmol Visual Sci 1979; 18: 848-55.

27 Arden GB, Vacgan, Hogg CR, Powell DJ, Carter RM. PatternERGs are abnormal in many amblyopes. Trans Ophthalmol Soc UK 1980; 100: 453-60)

28 Babel J, Stangos N, Korol S, Spiritus M. Ocular electrophysiology. A clinical and experimental study of electroretinogram, electro-oculogram and visual evoked response. Stuttgart: Thicme, 1977: 123-7.

29 Lennerstrand G. Delayed visual evoked cortical potentials in retinal disease. Acta Ophthalmol (Kbh) 1982; 60: 497-508.

30) Ikeda H, Tremain KE, Sanders MD. Neurophysiological investigation in optic nerve disease: combined assessment of the visual evoked response and electroretinogram. Br J Ophthalmol 1978 ; 62: $227-39$. 